\title{
Saçlı deride lokalize şişlik ile acil polikliniğine başvuran kız hasta
}

\author{
Çisem AKSU LIMON, Ayşe Deniz YÜCELTEN, Burak TEKİN, Neslihan BARANOĞLU HİM, Güniz YAŞÖZ, \\ Nilgün ERKEK
}

Üç yaş dört aylık kız hasta Ocak 2014'de çocuk acil polikliniğine kafada, saçlı deri üzerinde bir aydır büyümekte olan şşşlik yakınması ile başvurdu. Hastanın daha önce topikal ve sistemik antibiyoterapi kullandığı ancak toplu iğne başı kadar başlayan lezyonun giderek büyüdüğü öğrenildi. Fizik muayenesinde sol parietotemporal kemik üzerinde, yaklaşık $5 \mathrm{~cm}$ boyutlu,

yüzeyden kabarık, eritematöz, yer yer skuam ve pürülan akıntı içeren lezyon görüldü (Şekil 1,2,3). Dermatoloji Kliniği'ne danışılan hastadan alınan deri kazıntı ve saç örneklerinin potasyum hidroksit ile direkt incelemesi sonucu septalı hifler saptandı. Wood ışığı ile değerlendirmede hafif yeşil floresans görüldü. Ayrıca mantar kültürü için örnek gönderildi.

\section{Tanınız nedir?}
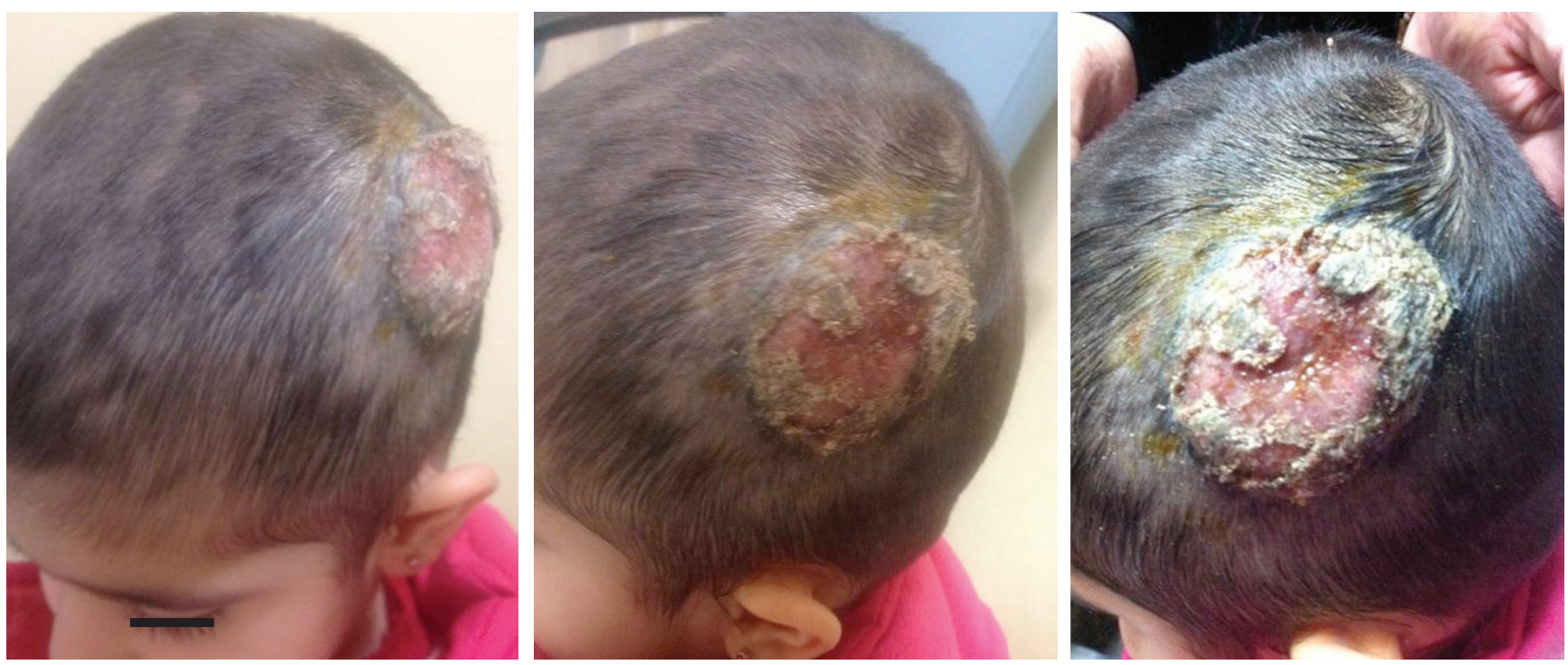

Şekil 1, 2, 3. Parietotemporal kemik üzerinde eritematöz, yer yer skuam ve pürülan akıntı içeren lezyon

Çisem Aksu Limon (四), Neslihan Baranoğlu Him, Güniz Yaşöz

Çocuk Sağlı̆̆ ve Hastalıkları Anabilim Dall, Marmara Üniversitesi Tlp Fakültesi Hastanesi, İstanbul, Türkiye

e-mail:drcisemaksu@hotmail.com

Ayșe Deniz Yücelten, Burak Tekin

Dermatoloji Anabilim Dal, Marmara Üniversitesi Tip Fakültesi Hastanesi, İstanbul, Türkiye

Nilgün Erkek

Çocuk Acil Bilim Dalı, Çocuk Sağllğı ve Hastalıkları Anabilim Dalı, Marmara Üniversitesi Tip Fakültesi Hastanesi, İstanbul, Turkey 


\section{Tanı: İnflamatuar tipte Tinea kapitis (Kerion selsi)}

Tinea kapitis yeryüzündeki dermatomikozların en yaygın görülen türüdür [1]. Puberte öncesi dönemde, 12 yaş altında sık izlenen Tinea kapitis prevelansının Türkiye'de \%0,03-0,8 arasında değiştiği bildirilmektedir [2]. Hastalık sıklığında, düşük sosyoekonomik düzey, kötü hijyen koşulları önemli rol oynamakta, geniş aileler ve kalabalık yaşam tarzı infeksiyon yayılımını kolaylaştırmaktadır [2]. Etken patojenler coğrafi dağılım farklılıkları göstermekle birlikte s1klıkla Trichophyton ve Microsporium türleridir [3]. Konak tercihlerine göre antropofilik, zoofilik ve jeolojik olarak tanımlanan etkenlerden antropofilik türler insandan insana direkt temas ya da sporla kontamine olmuş fomitler vasıtası ile bulaşırlar [1]. Zoofilik türler ise ülkemiz için halen önemli bir bulaş kaynağı olup petlerden ya da köylerdeki çiftlik hayvanlarından insanlara bulaşabilmektedirler [1]. On iki yaş altında sık gözlenen Tinea kapitis, puberte sonrası saçlı deri sebum yapısının değişmesi ve serbest yă̆ asitlerinin fungus büyümesini engelleyici etkisi nedeni ile nadir gözlenmektedir. Klinik olarak inflamatuvar olmayan Tinea kapitis superfisyalis, inflamatuar tip Tinea kapitis profunda (Kerion selsi) ve foliküler krutlar ile seyreden Tinea kapitis favosa tipleri bulunur [1]. Saçlı deri üzerinde etkileri saçta kırılıp, kepeklenmeden, skatrisyel alopesiye kadar değişebilir. Tanı klinik şüphe dışında direkt mikroskopik incelemede potasyum hidroksit ile hiflerin görülmesi ve mantar kültüründe etkenin üretilmesi ile konur [4]. Tedavide sistemik antifungaller önerilmektedir. Griseofulvin ilk seçenek olmakla birlikte ülkemizde bulunmaması nedeni ile terbinafin kullanılabilir. Tedaviye daha dirençli olması nedeni ile Microsporum enfeksiyonlarında dozunun iki katına çıkılması gerekebilir.

Itrakonazol ve flukonazol de özellikle Microsporum enfeksiyonlarında kullanılabilecek alternatifler arasındadır [4]. Sistemik antifungal tedaviye ayrica topikal antifungal krem ve şampuanlar eklenmesi önerilmektedir. Klinik yararı tartışmalı olmakla birlikte inflamasyonun baskılanması ve oluşabilecek skatrisyel alopesinin önlenebilmesi amacı ile tedaviye kısa süreli sistemik steroidler eklenebilir. Sistemik antifungal tedaviye klinik yanıt alınana ve kültür ve direkt inceleme ile mantar tetkiki negatif olana kadar 4-12 hafta süre ile devam edilmelidir [4].

Hastamızda, klinik ve mikroskopik bulgular ile inflamatuvar tipte tinea kapitis (kerion selsi) teşhis edilmiş; oral terbinafin $(62,5 \mathrm{mg} / \mathrm{kg} /$ gün$)$, tek doz triamsinolon asetonid $(1 \mathrm{mg} / \mathrm{kg})$ ve topikal ketokonazol krem ve şampuan önerilmiş ve 1 ay sonra kontrole çağırılmıştır. İlk kontrolde belirgin bir gerileme olmamakla birlikte takip eden altı aylık izlem süresince hastanın lezyonunun küçülerek saçlı deri hizasına yaklaşmaya başladığı görülmüştür (Şekil 4).

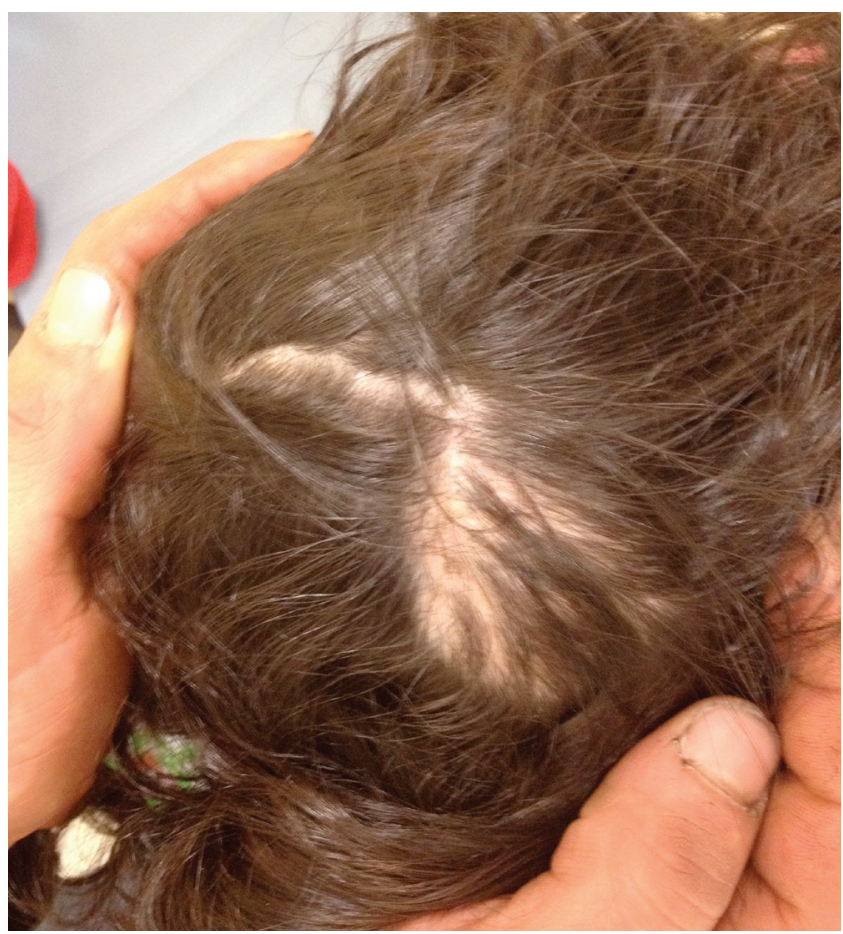

Şekil 4. Uygulanan tedavi ile altı aylık izlem süresinde lezyonun küçüldüğü görüldü.

Sonuç olarak, çocuk yaş grubunda bulaşma riski olan ve hijyen koşulları ile yakın ilişkili bulunan Tinea kapitis infeksiyonu halen günlük pratiğimizde hastamızda olduğu gibi ağır bir klinik ile karşımıza çıkabilmektedir. Hastaları değerlendirirken saçlı deri dışında diğer olası bulaş bölgelerini (sakal, kasık vb.) gözden geçirmek, ailenin diğer bireylerini muayene etmek büyük önem taşımaktadır. İnfeksiyonun tedavisini düzenlemek kadar toplumun hijyen konusundaki farkındalığını arttırmak ve indeks vakaları tespit ederek yayılımı engellemek de biz sağlık çalışanlarının görevleri arasındadır.

Aileden basım için onay alınmıştır.

\section{Kaynaklar}

1. Çalka Ö,Bilgili Güneş S, Karadağ AS, Önder S. Retrospective evaluation of 104 tinea capitis cases. Turk J Med Sci 2013; 43: 1019-23. doi:10.3906/sag-1211-9.

2. Hapçıŏlu B, Yeğenoğlu Y, Dişçi R, Erturan Z, Karayev Z. İstanbul'da farklı sosyoekonomik statüdeki ilköğretim öğrencilerinde tinea capitis ve pediculosis capitis prevelansının araştırılmas1. Türk Mikrobiyol Cem Der 2003; 33: 343-9.

3. Kakourou T, Uksal Ü. Guidelines for the management of tinea capitis in children. Pediatr Dermatol 2010; 27: 226-8. doi: 10.1111/j.1525-1470.2010.01137.x

4. Higgins EM, Fuller LC, Smith $\mathrm{CH}$. Guidelines for the management of tinea capitis. Br J Dermatol 2000; 143: 53-8. 